\title{
Coal Mine Monitoring System using Arduino and Lora
}

\section{P. Poornima, T. Bhavya Sai}

\begin{abstract}
Presently a day's of international warming and atmosphere adjustments there are testing circumstances in coal mineshaft. To diminish the incentive as properly as to enhance the productivity at the side of product high-quality the automation within the field of coal mine is necessary, as a way to also lessen the mine employees efforts. Because of numerous humans kicked the bucket in mine mishap, the mine wellbeing plays a key position in mine producing technique. By digital of new headways in the Web of Chimes, this paper proposes an smart tracking machine for coal mineshafts, which goals at checking the coal mineshaft produce system.
\end{abstract}

Keywords: incentive, automation, mine mishap, mineshafts.

\section{INTRODUCTION}

Underground mines are normally tremendous mazes, of which the passages are typically long and limited with some kilometers long and some meters in width. A great many mining employees are had to work below outrageous situations as indicated by the development necessities, and several diggers miners pass on from mining mishaps consistently.

\section{i. Existing System}

In Existing device, Coal mine protection systems are the usage of wired conversation. It is high-priced and makes problem to use wires in mines. Even measuring all parameters, it may crash if any catastrophe happens

\section{ii. Proposed System}

This undertaking is that IOT detects the uncertainty within the surroundings in beforehand using data evaluation reviews the scenario to the involved authority and the miners. The system additionally considers the emergency situations in hand to alert the miners quick as possible. This challenge serves the component of "Prevention is better than Cure" Easy to monitor \& manipulate by the use of LORA it's miles pretty green with lengthy variety communication IOT Protocol Communication SMS is despatched the usage of PUSH BULLET APP and information might be stored in cloud.

\section{iii. System Requirements}

a. Hardware Requirements

1. DHT11 sensor

2.Co2, smoke sensor

3. Heart beat sensor

Revised Manuscript Received on July 02, 2020.

Mrs. P. Poornima*, Assistant Professor, Department of Computer Science and Engineering, Mahatma Gandhi Institute of Technology, Hyderabad, India.

T. Bhavya Sai, Student, Department of Computer Science and Engineering, Mahatma Gandhi Institute of Technology, Hyderabad, India.

(C) The Authors. Published by Blue Eyes Intelligence Engineering and Sciences Publication (BEIESP). This is an open access article under the CC BY-NC-ND license (http://creativecommons.org/licenses/by-nc-nd/4.0/)

\author{
4.Methane sensor \\ 5.LORA pair \\ 6.Arduino \\ 7.node MCU \\ b. Software Requirements \\ 1.windows pc \\ 2.Arduino ide \\ 3.Embedded c \\ 4.Cloud
}

\section{DESIGN METHODOLOGY}

\section{i. Block Diagram}

Here we are going to do the coal miners protection gadget the usage of LORA and cloud why we are the usage of LORA due to the fact we don't have internet machine within the underground it is difficult to transmit the data accumulated by using the sensors by using the usage of LORA we can transmit the facts as much as $10 \mathrm{~km}$ however in our assignment we are the use of the range of $80 \mathrm{~m}$ because of fee problems and after acquire the data by node MCU in an effort to uploaded the information to the cloud and if the parameters reaches the threshold restrict we get SMS.

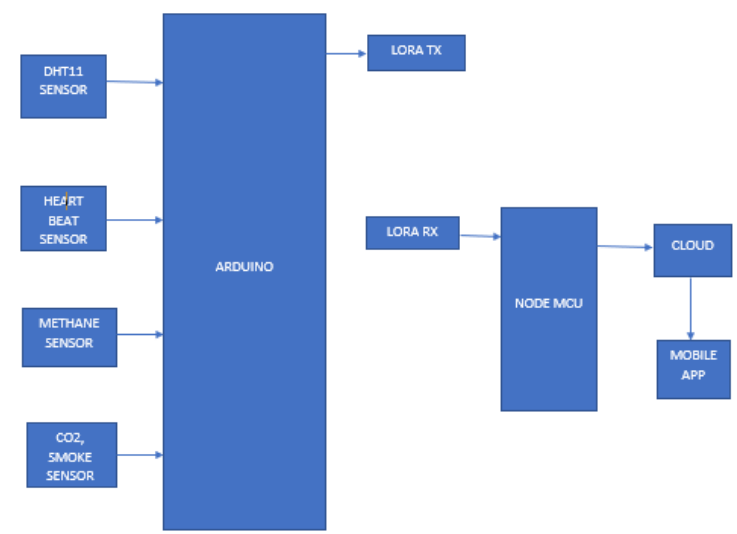

Fig.1.Block Diagaram for coal mine monitoring system using LORA

In Fig.1, sensors are connected to the Arduino and it collects the statistics from them. LORA transmiiter is hooked up to the Arduino in which as LORA receiver is attached to the node mcu it enables to shop the statistics in cloud. 


\section{SENSORS}

\section{i. DHT11 Sensor}

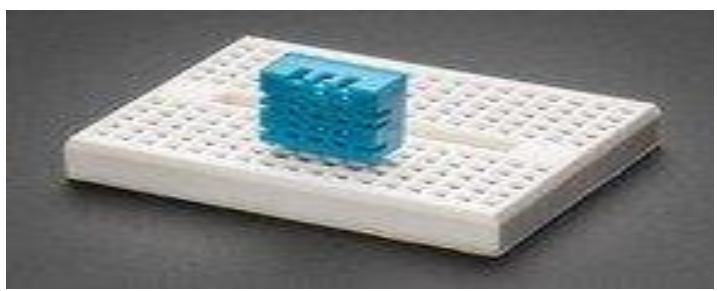

Fig.2 DHT11 sensor

The DHT11 sensor is a basic, ultra ease advanced temperature and dampness sensor. It utilizes a capacitive moistness sensor and a thermistor to guage the encompassing air, and lets out a computerized signal on the information pin (no simple info pins required). It is genuinely easy to apply, however requires cautious planning to snatch facts. The simplest genuine drawback of this sensor is you could simply get new records from it once each 2 seconds, so when the usage of our library, sensor readings may be as long as two seconds old.

\section{ii. Smoke Sensor}

Synergist globule sensors are utilized by and large to identify burnable gases. They have been being used for greater than 50 years. Initially, these sensors had been utilized for tracking gasoline in coal mines, in which they supplanted canaries that have been utilized for a protracted time period.

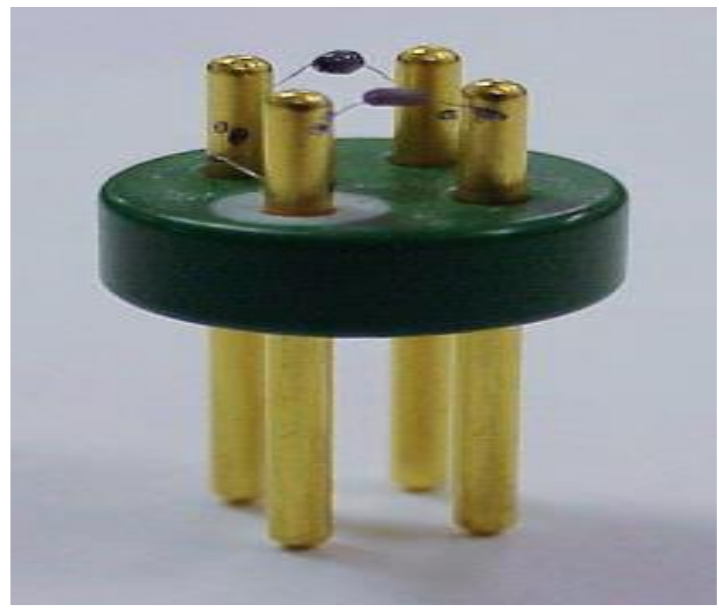

Fig.3 Smoke sensor

\section{iii. Heart beat Sensor}

Here you won't record the heart beat wave over a supply route however from the tip of the finger; this is known as fringe beat. It is recorded using a photoelectric heartbeat transducer, which estimates modifications in blood volume (plethysmography). A light source inside the transducer trans illuminates the fingertip, and a photoconductor recognizes modifications in mild intensity in the finger brought about by throb varieties in blood volume. Plethysmography is the most broadly utilized dimension approach for assessing fringe blood stream.

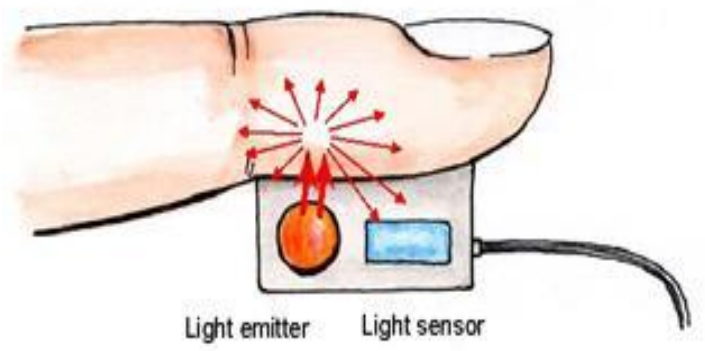

Fig.4 Optical finger plethysmograph

\section{iv. Methane gas Sensor}

Ideal sensor to be utilized to locate the nearness of a risky LPG spill in your automobile or in a provider station, garage tank condition. This unit may be effortlessly integrated into an alert unit, to sound a caution or give a visible sign of the LPG attention. The sensor has remarkable affectabilty blended with a brisk reaction time. The sensor also can experience iso-butane, propane, LNG and tobacco smoke.
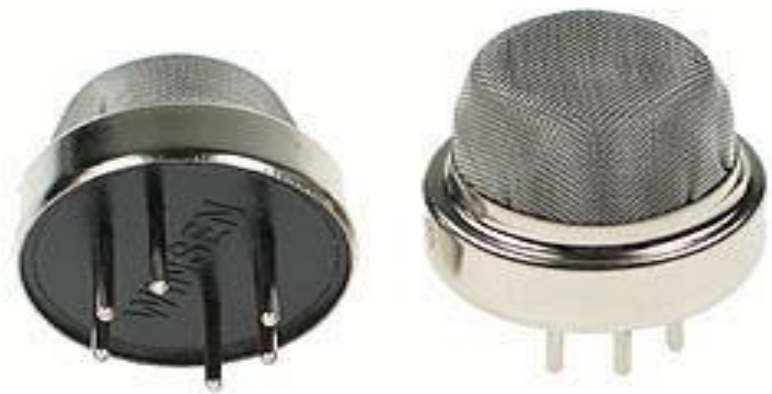

Fig 5: Methane gas sensor

\section{v. LORA}

LORA is a Long Range conversation module, which can be used for Long variety up to two KM based totally on serial Communication. It is applicable in many ways like Point to point communication or Node based totally verbal exchange Specification This Lora Module has Center Frequency of $868 \mathrm{MHz}$ with $20 \mathrm{DB}$ It has coverage variety up to $2 \mathrm{KM}$ It is Serial verbal exchange tool It has features like Point to Point, Repeaters by statistics hopping.

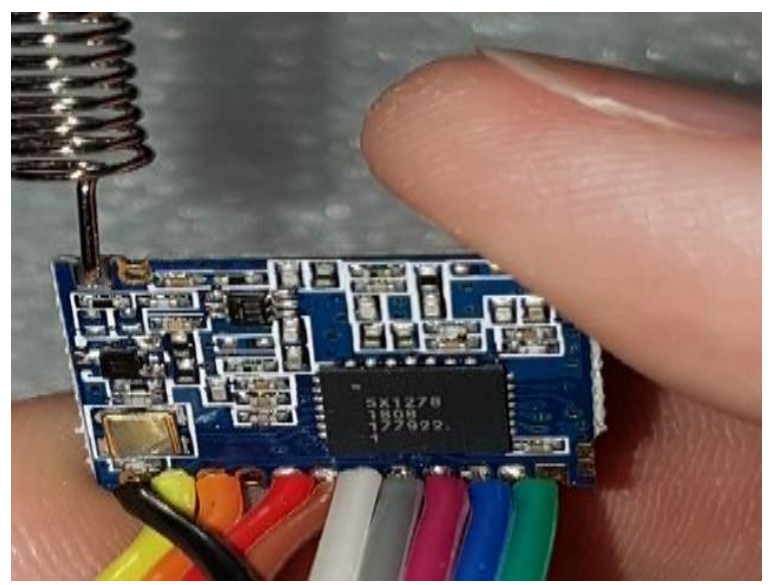

Fig 6: LORA

Published By:

Blue Eyes Intelligence Engineering and Sciences Publication

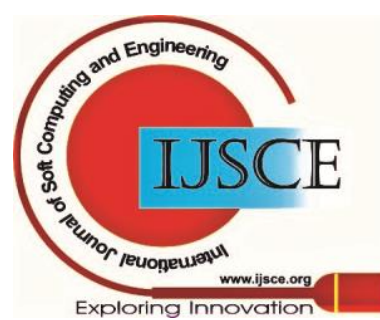




\section{vi. Node MCU}

The SDK affords a hard and fast of interfaces for records acquire and transmit capabilities over the Wi-Fi and TCP/IP layer so programmers can cognizance on utility development on the significant level. Clients can easily employ the corresponding interfaces to realize records acquire and transmit. All networking capabilities at the ESP8266 IoT platform are realized in the library, and are not obvious to customers. Instead, clients can initialize the interface in client foremost void consumer in $\mathrm{t}$ (void) is the default method gave.Clients can add functions like firmware initialization, network parameters putting, and timer initialization in the interface.

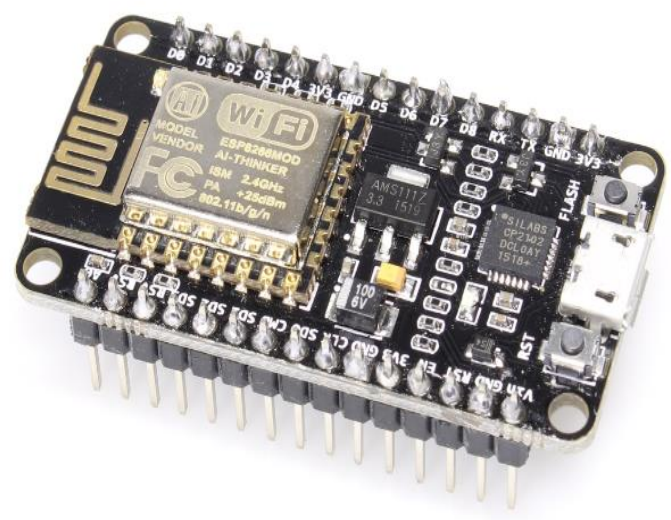

Fig 7: Node MCU

\section{SOFTWARE DESCRIPTION}

\section{i. Arduino Programming (IDE)}

The Arduino Coordinated Advancement Condition - or Arduino Programming (IDE) - contains a word processor for composing code, a message territory, a textual content support, a toolbar with catches for not unusual capabilities and a progression of menus. It interfaces with the Arduino and Genuine hardware to equipment to transfer programs and speak with them.

\section{ii. ThingSpeak cloud}

ThingSpeak is an IoT examination stage carrier that lets in you to total, imagine and examine live records streams inside the cloud. ThingSpeak gives immediate perceptions of facts posted by means of your gadgets to ThingSpeak. With the capacity to execute MATLAB code in ThingSpeak you may perform online examination and processing of the facts because it comes in. ThingSpeak is often utilized for prototyping and evidence of idea IoT structures that require investigation.

\section{RESULTS}

\section{i. Create a Channel}

Create a new channel in Thing Speak cloud.

In new channel, there are four fields naming temperature, humidity, gas, pulse.

\section{$\square$ ThingSpeak" channele * Apps community Suppart.}
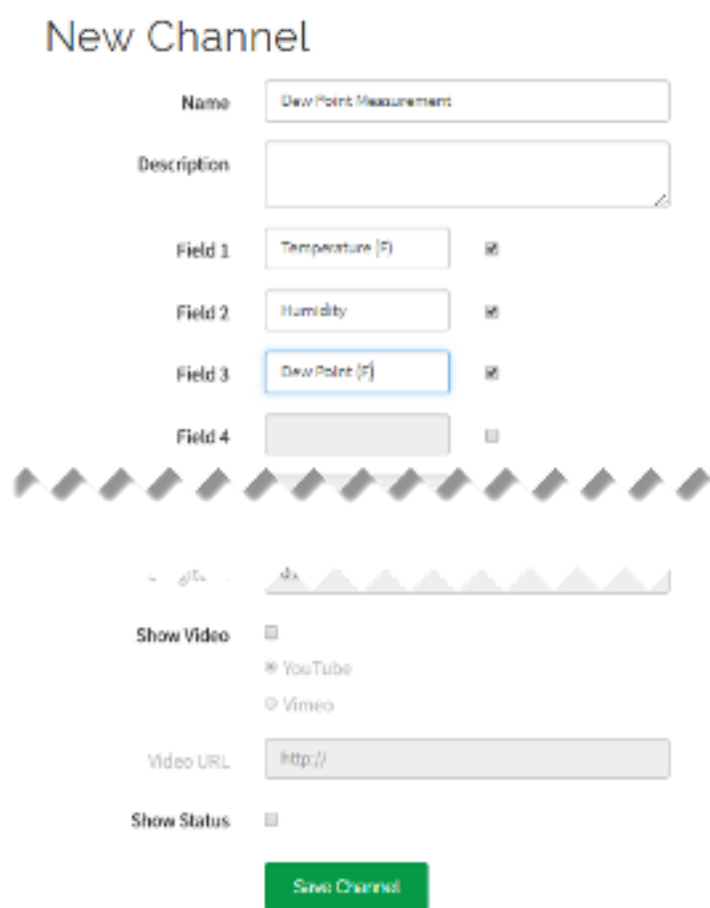

Fig 8: Channels of Thing Speak
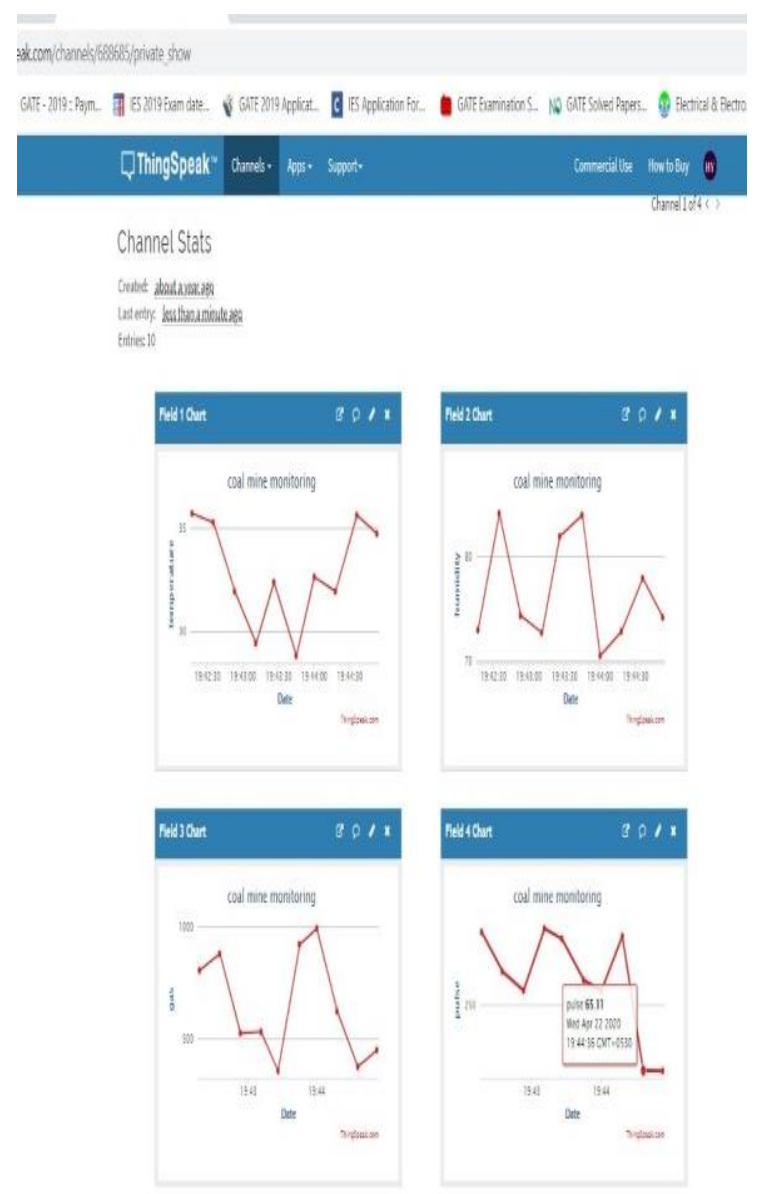

Fig 9: Field charts of ThingSpeak

Published By:

Blue Eyes Intelligence Engineering and Sciences Publication 
In Thing Speak cloud there will be two API keys namely read and right key. We need to copy the right API key which is 12-digit and paste that it into the receiver code. Inorder to set the threshold limit we need to click on apps section and select the react and set the value. To connect the push bullet app to cloud we need to copy the API key of it and paste it in the http section of cloud. To receive the alert message we need to set the settings accordingly. Then the results above are displayed.

\section{CONCLUSION}

This paper constructs a middleware for coal mineshaft security faraway tracking and manipulate perception. Concentrate on the structure and usage for underground remote sensor community arrangement, uniform gadgets get admission to framework, dispensed information dispersion service, event-driven supplier execution motor, and peaceful primarily based open programming interface. The predominant curiosity of this project is to expand a middleware for coal mineshaft tracking and control middleware which is straightforward to apply and deploy for engineers. Since the majority of the utility is Web-primarily based, any PC and an internet browser can interface the Web and enter the page to apply the application, and that could lessen the fees of coal mineshaft wellbeing tracking and control mechanization. Hence, it is predicted to be a primary commitment to coal mineshaft for better and more secure workplaces.

\section{REFERENCES}

1. K. Page, "Blood on the coal: The effect of organizational size and differentiation on coal mine accidents," J. Safety Res., vol. 40, no. 2 , pp. 85-95, 2009.

2. L. Mallet, C. Vaught, and M. J. Brnich Jr., "Sociotechnical communication in an underground mine fire: A study of warning messages during an emergency evacuation," Safety Sci., vol. 16, no. 5, pp. 709-728, 1993.

3. M. Ndoh and G. Y. Delisle, "Underground mines wireless propagation modeling," in Proc. 60th IEEE Veh. Technol. Conf., 2004, vol. 5, pp. 3584-3588.

4. O.Wood, J. Dykes, A. Slingsby, and K. Clarke, "Interactive visual exploration of a large spatiotemporal dataset: Reflections on a geovisualization mashup," IEEE Trans. Vis. Comput. Graph., vol. 13, no. 6, pp. 1176-1183, Nov.-Dec. 2007.

5. Q-G. Niu, X.-H. Huang, Z. Zhao, Y.-H. Zhang, C.-C. Huang, and L.Cui, "The design and evaluation of a wireless sensor network for mine safety monitoring," in Proc. IEEE GLOBECOM, 2007, pp. 1230-1236.

6. S. Li and Y.-H. Liu, "Underground coal mine monitoring with wireless sensor networks," ACM Trans. Sens. Netw., vol. 5, no. 2, pp. 1-29, 2009.

7. Z. Chen, Z.-C. Zhu, G.-B. Zhou, C.-F. Shen, and Y.-J. Sun, "Strategy of deploying sensor nodes in the chain wireless sensor network for underground mine," J. China Univ. Mining Technol., vol. 18, no. 4, pp. 561-566, 2008.

8. A. Bouguettaya, S. Nepal, W. Sherchan, X. Zhou, J. Wu, S.-P. Chen, D.-X. Liu, L. Li, H.B. Wang, and X.-M. Liu, "End-to-end service support for mashups," IEEE Trans. Serv. Comput., vol. 3, no. 3, pp. 250-263, Jul.-Sep. 2010

9. https://components101.com/dht11-temperature-sensor

10. https://www.ncbi.nlm.nih.gov/pmc/articles/PMC4517983/

11. https://www.hindawi.com/journals/js/2020/7192015/

12. https://robokits.co.in/sensors/gas-sensors/mq-4-methane-gas-sensormodule

13. The study of LORA low power and wide area network technologyUmber Noreen, Laurent clavier (2018).

\section{AUTHORS PROFILE}

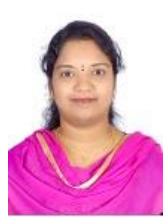

Mrs. P. Poornima, B. Tech (CSIT), M. Tech (CSE), has teaching experience of 14 years. Presently working as Asst Professor in the Department of Computer Science and Engineering, Mahatma Gandhi Institute of Technology, HYD. She has 6 research papers published in the International Journals of repute. She is the member of ISTE. Her research area consists of Image processing, Machine Learning, IoT, and AI etc.

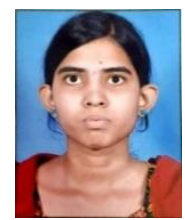

T. Bhavya Sai, Student, Bachelor of Technology (IV year) in Mahatma Gandhi Institute of Technology, Gandipet Affiliated to JNTUH 